\title{
MENONITAS BRASILEIROS ÀS MARGENS DO MUNDO NACIONAL: UM ESTUDO DE GEOGRAFIA SOCIAL E CULTURAL
}

Brazilian menonites on the edges of national world: a social and cultural geographical study

\author{
Wolf-Dietrich SAHR ${ }^{1}$ \\ Cicilian Luiza LÖWEN SAHR²
}

Transeuntes

da vida provisória:

que rumor de asas eternas

para além das fronteiras e dos símbolos!

Helena Kolody

Sempre Palavra (1985)

\begin{abstract}
RESUMO
Os menonitas são uma denominação religiosa com uma longa história de perseguição política e discriminação religiosa. Em conseqüência, desenvolveram, nos últimos 500 anos, uma cultura de migracão e transposição cultural. Na base da teoria de estruturação (Giddens), essa pesquisa apresenta uma interpretacão da relação conflituosa entre as integrações sistêmica e social dos menonitas, ambos com a sua sociedade de destino como dentro do próprio grupo. Teias familiares, pluralidade linguística, conflitos religiosos internos e a transformação econômica do meio rural ao meio urbano poderiam ser identificados como fatores importantes na transformação da sociedade menonita, em escala mundial como no caso de Curitiba, Paraná.

Palavras-chave: geografia social, geografia da religião, migração, menonitas, Paraná.
\end{abstract}

${ }^{1}$ Professor Visitante do Departamento de Geografia - UFPR - Doutor em Geografia pela Universidade de Tübingen - Alemanha.

2 Professora Adjunta do Departamento de Geociências da UEPG - Doutora em Geografia pela Universidade de Tübingen - Alemanha. 


\title{
ABSTRACT
}

\begin{abstract}
Mennonites are a religious group which often suffered from political prosecution and religious discrimination. In response, they have developed a flexible culture of migration and cultural transgression during the last 500 years. Based on the structuration approach (Giddens), this research interpretes the conflictuous relationship between systemic and social integration of mennonites in relation to their host societies and within the own group. Family network relations, linguistic plurality, internal religious conflicts, and economic transformation from rural and to urban spaces could be identified as some of the main features of transformations in the mennonite society, throughout the world and in Curitiba, Paraná.

Key-words: social geography, religious geography, migration, mennonites, Paraná.
\end{abstract}

A configuração social do Estado do Paraná é decorrente de um conjunto de processos de imigrações e integrações vividas durante os últimos 400 anos. Atualmente, este mosaico étnico transforma-se em um mapa fluído de culturas de transposição, as quais superam as antigas fronteiras étno-culturais. Isto ocorre pela influência de uma política brasileira integrativa e pela grande disposição da população para a miscigenação. O resultado é, assim, a formação de uma teia cultural de alta complexidade.

Um grande número de pesquisas já foi realizado sobre o papel da imigração no Estado do Paraná, destacando-se aquelas que investigam a preservação de elementos culturais nos grupos imigratórios (veja, entre outras, MARTINS, 1989; para alemães: WAIBEL, 1955 e OBERACKER, 1979; para poloneses: WACHOWICZ, 1981 e KOKUSZKA, 2000; para ucranianos: HORBATIUK, 1989 e ANDREAZZA, 1999; para italianos: MELLO NETO, 1998 etc.). Entretanto, busca-se ainda, até hoje, uma abordagem teórica que discuta adequadamente a transgressão de fronteiras culturais na atualidade e os processos de integração dos imigrantes. As teorias da estruturação de A. Giddens e da regionalização de B. Werlen parecem abordagens aptas a fornecer um instrumental terminológico apropriado para o melhor entendimento destes processos.

A integração dos imigrantes acontece, muitas vezes, através de culturas de transposição, as quais são desenvolvidas pelos próprios imigrantes com o objetivo de superar as suas restrições culturais. Como "cultura de transposição" entende-se, neste contexto, uma estrutura flexível que combina elementos culturais de origens diversas num jogo complexo de contradições e sincretismos. Este artigo procura mostrar, 
assim, para o caso dos menonitas brasileiros, como uma cultura de transposição contribui para a formação da sociedade brasileira.

Após uma breve introdução às teorias da estruturação e da regionalização cotidiana e de suas adaptações para o caso da migração, passa-se para a história geral dos menonitas e as tentativas de separação e integração destes em várias sociedades. Na seqüência são apresentados os elementos da regionalização cotidiana dos menonitas que moram na Região Metropolitana de Curitiba, finalizandose com o estudo de caso de uma família curitibana, que mostra de que maneira esta regionalização afeta os mundos vividos das pessoas.

\section{A MIGRAÇÃO NA TEORIA DA AÇÃO}

Conforme abordagem da teoria da estruturação (GIDDENS, 1989), este trabalho parte do pressuposto de que é o próprio migrante que está no cerne da migração. Ele reflete e decide sobre o ato de seu deslocamento baseado nas suas vontades, nos seus conhecimentos e nas suas expectativas. Assim, a migração não representa primordialmente um fato social ou um projeto político, mas sim, um ato individual, subjetivo e conscientemente realizado. Este ato, entretanto, está inserido num contexto de estruturas sociais.

Como "estruturas sociais" entendem-se os sistemas de significação, dominação e legitimação (GIDDENS, 1989, p. 22 et. seq.; CLOKE et al., 1991, p. 103). Os sistemas de significação são, por exemplo, a língua, a música, a literatura, a dança, a religião, a filosofia, os gestos corporais e os ritos, ou seja, todos os sistemas sígnicos que pertencem a um determinado universo social e os quais são utilizados para manter a comunicabilidade social. Sistemas de dominação são geralmente recursos. Existem, de um lado, recursos alocativos ou materiais, necessários para manter ou modificar a sobrevivência de um determinado grupo social (alimentos, roupas, dinheiro, meios de produção etc.), e de outro, recursos autoritários que se compõem de relações sociais (parentesco, vizinhança, teias de poder, vínculos empregatícios e outros). Os sistemas de legitimação são costumes, tradições, leis e éticas que podem ser vistos como uma mistura entre códigos semióticos e relações sociais ficando, conseqüentemente, numa posição intermediária entre os campos da significação e da dominação (SAHR, 1998, p. 225). 
A formação cultural do indivíduo, a sua identidade, surge através da dialética que rege Estrutura e Agir. Cada ato contém, como recurso e conseqüência, estruturas das mais variadas. Atos são efetivados em determinados momentos e implicam uma modificação da própria estrutura. O caso da língua é revelador: no ato de falar o indivíduo recorre à gramática e ao vocabulário de uma língua, mas nunca com a intenção de transformá-los. Todavia, o costume de modificar parcialmente a língua através de sotaques, socioletos ou dialetos por determinados grupos sociais, mostra que o uso mais abrangente de uma língua cria sistemas linguísticos modificados com base em regras próprias. Conseqüentemente, não se pode pensar numa Estrutura sem a sua efetivação pelo Agir, mas também não existe Agir sem Estrutura. GIDDENS (1989, p. 13 et seq.) chama este processo de "estruturação" e identifica-o como o elemento principal na formação de uma sociedade.

O Agir pode conter duas intenções: a primeira refere-se à construção de uma relação social quando o ato dirige-se diretamente a outro agente; a segunda compreende a manutenção da própria estrutura sistêmica. Essas estruturas são necessárias porque fornecem um veículo adequado para realizar contatos sociais (GIDDENS 1989, p. 22). O conjunto das duas intenções resulta numa dualidade da estrutura - ela aparece igualmente como instrumento e/ou como fim de uma ação. Em conseqüência, existem duas formas de integração: uma criada pelas relações sociais imediatas dentro de um grupo social e no mundo vivido do agente (ver SCHUETZ/LUCKMANN, 1979), denominada integração social, e a outra na qual predomina o interesse da manutenção da estrutura (HABERMAS, 1981, p. 226 et seq.; SAHR 1998, p. 216), caracterizada como integração sistêmica. Quando a segunda prevalece à primeira, pode-se falar, conforme HABERMAS (1981, p. 293), de uma "colonização do mundo vivido pelas forças sistêmicas".

No caso do imigrante, a dualidade da estrutura apresenta-se ainda mais complexa. O imigrante dispõe simultaneamente, via de regra, de várias estruturas sistêmicas, sejam elas duas línguas, elementos culturais de diversos países, relações sociais das regiões de origem e de destino, inserções em contextos econômicos diversificados, etc. Nessa condição, a construção do seu mundo vivido e da sua cultura pessoal acontece no momento em que ele consegue mediar as tensões e contradições da multiplicidade das estruturas de sua vivência. O próprio estrangeiro torna-se, assim, criador e agente de uma cultura de transposição entre o próprio mundo e o mundo forasteiro (ver WALDENFELS, 1997, p. 66). 
O geógrafo suíço B. WERLEN (1997) incorporou a teoria da estruturação à sua proposta de uma geografia das regionalizações cotidianas. Como Giddens, ele coloca o Agir como o ponto de partida de suas reflexões para entender a configuração do espaço. Conseqüentemente, ele vê no indivíduo um agente competente que se exprime espacialmente através do seu corpo e dos resultados dos seus atos. Em conjunto com outros agentes da sociedade, o indivíduo negocia (às vezes com conflitos, às vezes pacificamente) o espaço disponível para a construção do seu mundo vivido. O espaço é, portanto, o resultado de uma regionalização que - ao contrário da idéia tradicional da geografia - fica permanentemente flexível e reversível (WERLEN, 2000, p. 351).

No caso do imigrante, essa negociação do espaço vivido acontece com duplas referências. Tanto a estrutura do país de origem quanto a do de destino tornam-se recursos na luta pela sua sobrevivência. Com este sincretismo, de um lado, o imigrante ameaça involuntariamente o funcionamento da integração sistêmica no país de destino, fato este que poderia explicar, embora não justifique, as reações adversas a imigrantes em vários países do mundo. De outro lado, o enfraquecimento das estruturas sistêmicas no país de destino pela ação dos imigrantes possibilita a flexibilização e adaptação dessas estruturas às novas soluções sociais baseadas numa cultura de transposição. Com isso, os grupos imigratórios contribuem significativamente para o fortalecimento da integração social no seu novo país.

Três dimensões de regionalização do migrante podem ser identificadas. A primeira dimensão é o círculo familiar e de amizades,onde predominam relações diretas e imediatas, favorecendo a integração social, principalmente no campo da dominação, onde se constrói o mundo vivido do migrante através da inserção econômica, da inter-relação social e dos laços afetivos com a nova sociedade (empregos, casamentos, amizades etc.). A segunda dimensão aponta o próprio grupo sócio-cultural do migrante como base de atuação e depende geralmente da integração sistêmica no campo sígnico da cultura originária. Aqui se preservam elementos como tradições e histórias. A terceira dimensão refere-se ao contexto geral do país de destino, com os seus discursos legitimadores, sejam eles do Estado, da Igreja, da economia ou da ética. Nesta dimensão, o migrante depende muito dos seus próprios conhecimentos sobre o funcionamento destes discursos. Ele mesmo, com consciência e na busca da sua identidade como migrante, negocia, caso por caso, as tensões entre ambas as culturas, criando assim, em conjunto com seus co-migrantes, uma nova cultura de transposição. 


\section{A DIVERSIDADE DOS PROCESSOS DE REGIONALIZAÇÃO NA HISTÓRIA MENONITA}

Este trabalho procura investigar a regionalização do mundo vivido de imigrantes menonitas e a sua inserção na Região Metropolitana de Curitiba, Paraná. Os menonitas têm uma história de 500 anos de regionalizações cotidianas em ambientes estrangeiros e tornaram-se, assim, grandes especialistas na formação de culturas de transposição. Desde o surgimento do movimento anabatista, este grupo vivenciou perseguições religiosas e políticas por causa de suas convicções. Eles desenvolveram, com isso, uma cultura que se preocupa muito com a preservação de tradições, negociando permanentemente a sua adaptação aos contextos forasteiros. Conseqüentemente, os menonitas criaram configurações sociais diferenciadas e flexíveis nas suas respectivas sociedades em todos os níveis de atuação: na família, no âmbito étnico-religioso e nos seus respectivos países. Recentemente, essa temática chamou bastante atenção para os pesquisadores da história e sociologia menonita (veja URRY, 1999, KNISS, 1999) o que justifica uma interpretação mais detalhada deste assunto com base na teoria da estruturação.

A origem dos menonitas se reporta ao ano 1525, quando um pequeno grupo de protestantes urbanos questionava, na cidade suíça de Zurique, a atuação da Igreja Católica e igualmente dos líderes da Reforma (Zwinglio). A discussão era principalmente sobre a questão da responsabilidade do cristão. Enquanto as igrejas estatais destacaram a importância do Estado para com o cristão através do batismo das crianças, este grupo insistia que cada crente decidisse autonomamente sobre a sua relação com Deus. Por isso, defendiam o batismo apenas na fase adulta. Muitas pessoas foram, assim, batizadas pela segunda vez, recebendo da sociedade o nome de anabatistas (MARTINEZ, 1997). A rejeição da intervenção do Estado em questões religiosas fez surgir graves conflitos com o governo local, resultando numa forte perseguição a partir de 1526.

Muitas famílias anabatistas refugiaram-se na Moravia, onde formaram comunidades rurais com terras comuns e escolas de ensino religioso. Lá, eles reproduziam as idéias das primeiras comunidades cristãs apostólicas. Eram chamados huteritas em função do nome de seu líder Jakob Huter. A integração social dos huteritas baseou-se numa complexa configuração social (grupos de famílias em comunidade fraternal), econômica (Bruderhof = propriedade rural comunal) e ideológica (teologia anabatista). Assim, eles conseguiam montar, no 
contexto de um ambiente exterior bastante libertário, uma forte integração social e sistêmica entre eles (PENNER, 1955, p. 38 et seq.).

A partir de 1530, a mensagem do anabatismo foi levada para o norte da Alemanha e para os Países Baixos. Nesta região, um padre católico renegado, Menno Simons, começava a organizar clandestinamente grupos urbanos e rurais de crentes anabatistas, denominados menonitas por seus adversários protestantes (PENNER, 1955, p. 48 et seq.). Nos Países Baixos, os menonitas permaneceram economicamente integrados à sociedade geral exercendo as suas profissões como tecelões e comerciantes na região de Flandres ou como agricultores, engenheiros e mercadores na região da Frísia e Holanda. Neste caso, a sua integração sistêmica e social interna era exclusivamente religiosa. Não houve intervenção política nas suas vivências por causa da liberdade religiosa vigente no país (CANADIAN MENNONITE ENCYCLOPEDIA E338ME).

Com uma perseguição crescente a partir de 1550, dominantemente na parte espanhola católica de Flandres, muitos menonitas deslocaram-se para a Prússia polonesa na região do baixo Rio Vístula, onde encontraram alguns grupos de huteritas. Por causa do seu conhecimento tecnológico sofisticado, eles conseguiram drenar os manguezais do delta do Rio Vístula e estabeleceram-se nessas áreas como agricultores. Formou-se um sistema de colonização dirigida com aldeias de casas isoladas. Cercado por agricultores alemães e eslavos, eles formaram - como anteriormente os huteritas na Moravia - uma estrutura social e sistemicamente integrada, baseada numa economia agrícola avançada. Preservaram a sua língua holandesa, a religião e as suas estruturas familiares, rejeitando casamentos com membros de fora da comunidade.

Apenas a partir de 1757 é que os cultos passaram a ser proferidos em língua alemã, sinal de uma integração maior na sociedade geral. Pouco tempo depois, esta região foi incorporada ao reinado alemão da Prússia (1772), intensificando-se, assim, as tentativas do governo de integrar os menonitas ao sistema nacional. Em 1780, eles foram obrigados a prestar o serviço militar, atividade geralmente rejeitada por causa da ideologia pacifista dos menonitas. Um edito de 1789 proibiu ainda a expansão de suas terras por compra. Essas constantes e profundas invasões pelo governo ao mundo vivido dos menonitas ameaçavam a sua integração sistêmica interna. Como reação, desencadeou-se um verdadeiro êxodo para novas regiões da Europa (GERLACH, 1992, p. 27 et seq.). 
Nessa época, a imperatriz russa Catarina, a Grande, tinha estabelecido uma política de colonização dirigida às estepes da Ucrânia, em áreas recém conquistadas do Império Otomano. Os menonitas foram convidados preferenciais, pois os soldados russos já haviam conhecido suas obras no vale do Rio Vístula durante a guerra dos 7 anos (17561763). No início, foram principalmente menonitas pobres, sem terra, que responderam ao convite. A inexperiência destes como agricultores dificultou bastante sua implantação nas novas regiões em meio a russos, cossacos, tártaros, ucranianos, judeus e alemães. Os menonitas dirigiam-se a partir de 1788 para a região de Chortitza (Zaporozh'ye no baixo Dnieper) e, depois de 1803, para a região da Molotchna (Melitopol, também no baixo Dnieper). Mais tarde, em 1850 e 1861, alguns migraram também para Saratova e Samara na região do Rio Volga (WISOTZKI, 1992, p. 42 et. seq.).

Para facilitar a sua instalação, os menonitas receberam vários privilégios da imperadora russa, tais como: liberdade religiosa, autogoverno e autocontrole econômico. Os seus povoamentos eram construídos ao longo de estradas com casas isoladas, iguais às picadas brasileiras. Nos centros das respectivas regiões surgiam pequenos lugares centrais: Chortitza, Neuendorf, Halbstadt e Gnadenfeld. As regiões dos menonitas mostravam uma forte coesão social interna, devido a um sistema de governo democrático, com prefeitos e secretários eleitos, um sistema escolar sofisticado, em língua alemã e a possibilidade do exercício da religião. O estabelecimento de cooperativas por um dos seus líderes, Johann Cornies e o uso coletivo dos seus lucros, possibilitaram a manutenção de um serviço social com escolas, lares, orfanatos e programas de apoio aos pobres, em conformidade com a base ideológica da ajuda mútua do cristão. No final do século XIX, a freqüência às escolas era obrigatória e o ensino era dado em alemão oficial (Hochdeutsch), e não no dialeto comum dos menonitas (Plaudietsch). Assim, a coerência social e sistêmica foi internamente quase completa neste "Estado" dentro do Império Russo, num ambiente com características predominantemente rurais (PENNER, 1955).

Curiosamente, essa coerência social não foi reproduzida no âmbito religioso. Já no século XVIII observa-se uma forte fragmentação da igreja menonita. Um conflito trazido da Prússia, entre flamengos e frisões, continuou na Rússia. Não era um conflito étnico, mas sim, uma disputa teológica-litúrgica. Os flamengos, de origem urbana, preferiam formas mais igualitárias na comunhão com o líder religioso integrado na comunidade, enquanto os frisões, com uma história mais rural, 
destacavam uma certa superioridade do Prediger (=pregador). Os flamengos e frisões, em geral, viviam em aldeias diferentes na Rússia.

Em 1812, separou-se na Molotchna a Pequena Igreja Menonita, um grupo que insistia numa vivência cristã mais pura, que defendia o uso exclusivo da Bíblia e de livros religiosos e que rejeitava o consumo de álcool e fumo. Na sua ideologia, era indispensável uma separação nítida entre o Império deste mundo e o de Deus. Em 1860, criou-se em Gnadenfeld (também na Molotchna) um outro grupo pietista de menonitas denominado Irmãos Menonitas, que criticou a prática da igreja convencional por batizar o crente após ele ter proferido um credo formal. Eles insistiam no batismo como decisão individual do adepto e, portanto, o credo deveria ser espontâneo. Simbolicamente, este grupo favoreceu o batismo por submersão ao batismo com jarro, como era costume à época. Até hoje, os grupos da Igreja Menonita convencional e da Igreja Irmãos Menonitas coexistem lado ao lado (WISOTZKI, 1992, p. 82 et seq.).

A partir de 1870, as situações política e econômica dos menonitas na Rússia dificultaram-se bastante. Iniciou-se uma nova onda de emigração em conseqüência da falta de terras para manter o sistema agrário, de disputas internas sobre a ideologia religiosa e de uma nova lei russa que estabelecia o serviço militar obrigatório (WISOTZKI, 1992, p. 49). Até 1880 , cerca de 18.000 menonitas tinha deixado este país, dirigindo-se principalmente para os Estados Unidos e o Canadá.

A Revolução Russa em 1917 agravou a situação ainda mais. A política oficial contra o campesinato, que representava a base econômica dos menonitas até este momento, as ameaças contra a religião em geral e a ideologia comunista claramente antipacifista fizeram que, em 1922, cerca de 21.000 menonitas deixassem o país em direção ao Canadá (PENNER ,1955, p. 156). O golpe final veio da política estalinista na fase da coletivização, a qual destruiu completamente a integração socioeconômica dos menonitas e impossibilitou, assim, a manutenção da sua cultura. Muitos se refugiaram no interior da União Soviética, outros foram levados para regiões desconhecidas, outros assassinados, aprisionados ou simplesmente sumiram. Apenas 6.000 refugiados conseguiram sair do país com a ajuda do governo alemão, entre eles, encontravam-se os ascendentes dos menonitas do Brasil (KLASSEN, 1995, p. 25 et seq.).

Até este momento, a história dos menonitas foi caracterizada pela permanente insistência numa integração sistêmica interna intensiva, a qual garantiu a sobrevivência do grupo social, fortalecendo, assim, também os laços entre as comunidades (integração social interna). Este 
comportamento impediu, em grande parte, uma integração social maior ao conjunto dos países onde eles moravam. Cada crise que ameaçava a coerência interna do grupo, era respondida pelos menonitas por uma intensificação do seu isolamento social. Isto explica, de certa forma, as divergências internas no âmbito religioso.

\section{A REDE DOS MENONITAS NO BRASIL}

A experiência traumática da fuga da União Soviética fez com que os menonitas do Brasil tentassem novamente reconstruir a sua estrutura social interna, como já haviam feito muitas vezes anteriormente na sua história. Em agosto e setembro de 1929, encontraram-se 12.000 menonitas em Moscou. Eles tinham deixado tudo na Ucrânia e não sabiam para onde ir, não agüentando mais as pressões do governo comunista com sobretaxações e ameaças físicas. Negociações do governo alemão com os governos brasileiro e russo, a disposição da "Hanseatische Kolonistationsgesellschaft" (=Sociedade Colonizadora Hanseática) em Santa Catarina de receber até 6.000 colonos e a ajuda financeira da organização alemã "Brüder in Not" (=Irmãos em Necessidade) e de menonitas dos Estados Unidos e dos Países Baixos, possibilitaram a transferência provisória de 6.000 refugiados para Alemanha. Outros 12.000 foram deportados por Stalin para a Sibéria ou simplesmente desapareceram (KLASSEN, 1995, p. 45 et seq.). Do contingente alemão, 1.300 conseguiram a emigração para Santa Catarina (PENNER, 1955, p. 202).

"A mudança de um agricultor do estepe, com uma lavoura mecanizada e um clima continental, para uma agricultura silvícola primitiva e meramente manual, nas condições de um clima sub-tropical, representou um desafio difícil de ser enfrentado." (PAULS, 1980a, p. 35). Foi, entretanto, exatamente diante deste desafio que os menonitas se depararam quando chegaram ao Brasil. Entre 1930 e 1932, instalaram-se 802 pessoas (=141 famílias) em Ibirama (Rio Krauel no Alto Vale Itajaí, SC), espalhados em três núcleos: Witmarsum (originalmente o nome do lugar de nascimento de Menno Simons), Waldheim (=Lar da Floresta) e Gnadental (=Vale de Graças) (PAULS, $1980 a$, p. 48). Um outro povoamento surgiu na vizinhança destes núcleos, no "Stoltzplateau" (=Planalto do Stoltz), denominado Auhagen, com 504 pessoas (=03 famílias). Para os imigrantes tudo era novo neste ambiente: a selva, os índios, a cultura brasileira, etc. (PAULS, 1980b). Precisavam aprender uma agricultura tropical, uma nova forma de 
construir casas, como as cabanas dos caboclos, e também a conviver com os índios xokleng, kaingang e guarani e com os Cafuzos. Os recémchegados encontraram na nova região também outros colonos europeus da Sociedade Colonizadora Hanseática, como luteranos e católicos de ascendência alemã, italianos do Trentino e luso-brasileiros (GOULART; FRAGA, 2000).

Neste ambiente multi-cultural, longe da civilização conhecida da Ucrânia, os menonitas tentaram reorganizar-se socialmente em cooperativas, escolas e grupos religiosos, como haviam feito na antiga Rússia. Todavia, a pressão psicológica de um abandono total e o constrangimento com uma realidade desconhecida, aumentaram os conflitos internos tanto no sistema religioso - entre as comunidades da Igreja Menonita e dos Irmãos Menonitas - como no sistema econômico - na cooperativa (Sociedade Cooperativa Witmarsum). Um agravante geográfico para essas divisões foi ainda o fato de que a estreiteza do vale não permitia uma colonização densa ao longo da estrada, distanciando as casas, o que dificultou bastante o intercâmbio entre os colonos. $\mathrm{O}$ afastamento dos centros de cultura brasileira fortaleceu as tendências segregacionistas dos menonitas, resultando no uso quase exclusivo das suas línguas tradicionais (alemão oficial e Plaudietsch) e na manutenção autônoma do seu sistema escolar (KLASSEN, 1995). Quase todos os menonitas estavam convencidos de que os problemas da integração social apenas poderiam ser superados através de uma da forte integração sistêmica interna da cultura menonita.

Todavia, já em 1931, o menonita Jacob Goosen, de Auhagen do "Stoltzplateau", tinha explorado a região de Curitiba e, em conseqüência, mudou-se para lá, seguido de vários outros membros da comunidade (PAULS, 1980a, p. 193). Nos campos de Curitiba, os menonitas encontraram uma paisagem semelhante a da região da Ucrânia setentrional e onde poderiam, além disso, conviver com outros imigrantes alemães também de origem russa. Essas semelhanças culturais e ambientais com a antiga pátria incentivaram uma crescente emigração para Curitiba, não só do núcleo de Auhagen, mas também de outros lugares de Santa Catarina. Desta forma, a integração social externa à sociedade brasileira foi facilitada por estas experiências históricas dos menonitas.

A partir de 1934, várias famílias de Santa Catarina chegaram à Vila Guaíra, na periferia de Curitiba, iniciando a formação de uma comunidade religiosa significativa no meio urbano (KLASSEN, 1998, p. 30). Em 1936 e 1937 surgiram, mais distante da cidade (7 km), três aldeias de caráter rural com enfoque na produção leiteira, estas se 
localizavam na antiga Fazenda do Boqueirão e no Xaxim (p. 31 et seq.). Estas aldeias foram incorporadas à malha urbana de Curitiba durante os anos sessenta de tal forma, que a maioria dos seus moradores foram inserindo-se economicamente na cidade e no bairro, tanto através de empregos fixos, como na sua transformação em empresários urbanos. Vários dos moradores rurais lotearam as suas propriedades, contrariando, desta forma, a antiga regra dos menonitas de não morar em conjunto com não-menonitas.

Nos anos cinqüenta, a crise agrícola e social dos moradores que permaneceram nos núcleos de Santa Catarina agravou-se tanto, que eles também passaram a buscar novas perspectivas. Isto resultou na fundação dos núcleos Colônia Nova em Bagé (RS) e de Witmarsum no Segundo Planalto paranaense (município de Palmeira). Ambas as colônias, localizadas em áreas planas aptas à produção de trigo e à criação de gado leiteiro, possibilitaram o exercício de uma agricultura mais mecanizada e moderna, tão desejada pelos colonos (ver MARTENS, apud PAULS, 1980a, p. 136-189; PAULS 1980a, p. 94-136). Observa-se que o grupo do Krauel de Santa Catarina acabou divididose e com isto acirrou-se uma divisão religiosa, dando preferência à integração sistêmica em relação à integração social. Os membros dos Irmãos Menonitas queriam afastar-se dos processos da secularização que alegavam existir dentro da comunidade catarinense e, por isso, preferiram afastar-se para um contexto isolado no Rio Grande do Sul. Já os membros da Igreja Menonita buscaram a comunidade e vizinhança com os seus correligionários urbanos em Curitiba, favorecendo, assim, a integração social (KLASSEN, 1998, p. 53). Hoje, ambas as comunidades rurais, a de Bagé e a de Palmeira, estão bem integradas no seu respectivo ambiente brasileiro e participam ativamente na vida comunitária dos seus municípios, trocando gradativamente a isolação sistêmica por uma integração social com o ambiente externo.

A urbanização crescente da metrópole de Curitiba, como nos bairros do Boqueirão e do Xaxim, pode ser vista como uma intrusão do sistema capitalista no "mundo dos menonitas", através da especulação imobiliária. Como conseqüência, a integração geográfica dos menonitas alterou-se significativamente. Os seus lotes e propriedades ficaram dispersos entre outros moradores migrantes, originários de outras áreas rurais ou urbanas do Estado ou de outras regiões do Brasil. Como reação, os menonitas passaram a dar maior atenção aos seus lugares de encontros, como as igrejas, as escolas e as cooperativas, transformando o espaço geográfico menonita, que antigamente era homogêneo, numa rede social mantida através de contatos pessoais. 
Hoje, as comunidades menonitas não representam mais o elemento dominante dos bairros do Boqueirão e Xaxim, apesar do fato de instalações como o Colégio Erasto Gaertner ou a Praça Menonita terem se tornado marcos importantes na paisagem urbana de Curitiba.

Essa fragmentação espacial reaproximou socialmente as diferentes correntes religiosas, as quais encontraram uma base de convivência nos postulados da Bíblia, principalmente na Primeira Epístola do Apóstolo Paulo aos Coríntios, Cap. 12: "Pois num só espírito todos nós fomos batizados para sermos um só corpo e ...bebemos do mesmo Espírito" (v. 13). O fortalecimento da integração social dos menonitas possibilitou a superaração dos purismos separatistas e levou a uma integração sistêmica no campo da religião. Na atualidade, as divergências sistêmicas aparecem mais no interior das famílias anabatistas e sobre assuntos seculares. Pode-se falar de uma privatização e secularização dos antigos conflitos. Para entender melhor este fenômeno sociológico recorre-se a seguir a uma pesquisa qualitativa, utilizando o caso de uma família.

\section{UMA FAMÍLIA MENONITA DO XAXIM}

A família menonita escolhida tem membros morando no bairro do Xaxim em Curitiba. Quase todas as características do grupo menonita que veio da União Soviética podem ser observadas nestas pessoas: a história familiar com percurso migratório da Rússia até o Brasil, as transformações na língua, as disputas religiosas e a modificação na base econômica. Como ponto de partida para esta análise encontramse duas pessoas de referência, tratam-se das irmãs Gertrud* e Isabel* (nomes fictícios), que pertencem à terceira geração dos menonitas brasileiros. Ambas, com idade entre 55 e 65 anos, são casadas com integrantes da Igreja dos Irmãos Menonitas e possuem quatro e três filhos respectivamente. O único irmão delas, falecido durante os anos sessenta, fez um casamento católico e deixou três filhos. Enquanto as duas irmãs mantêm fortemente a cultura menonita nas suas famílias, os descendentes do irmão perderam gradativamente estas características, incorporando traços da cultura brasileira.

O avô das duas irmãs, Aron*, fez parte da grande leva dos menonitas que veio para o Brasil em 1929. Aron* teve sete filhos, destes apenas três o acompanharam para o Brasil (ver figura 1). Entre estes estava David ${ }^{*}$, pai de Gertrud* e Isabel*. Três permaneceram na União Soviética e um na Polônia. Nessa geração parental, todos se casaram. 
Os filhos daqueles que vieram para o Brasil aqui permaneceram. Os daqueles que ficaram na União Soviética, mudaram-se, entre os anos 1960 até 1985, para a Alemanha e o Canadá. Os filhos daquele que permaneceu na Polônia, foram juntamente com o pai para o Canadá. Aron* teve 32 netos (geração filial), que proporcionaram a continuidade de sua família.

FIGURA 1 - ARVÓRE GENEALÓGICA DE FAMÍLIA MENONITA COM INDICAÇÃO DO PERCURSO MIGRATÓRIO DE SEUS MEMBROS

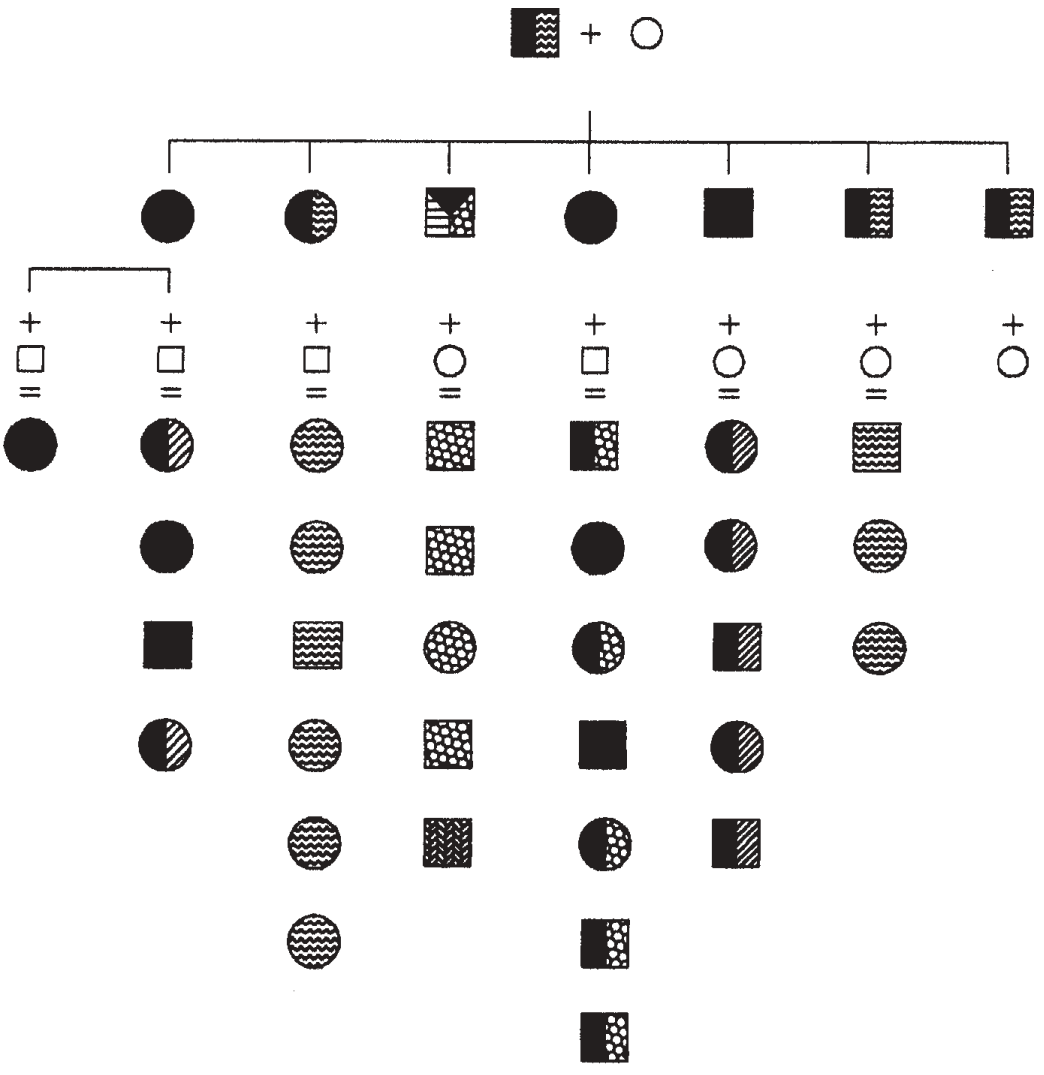

LEGENDA

SEXO
$\square$ Masculino


Os lugares de moradia dos membros desta família mostram uma verdadeira micro-globalização: três grupos moram no Brasil e se concentram em Curitiba; dois grupos encontram-se na Alemanha na região de Hanover, embora membros destes permaneçam ainda na Rússia e Ucrânia; e dois grupos estão no Canadá, morando nas grandes concentrações menonitas em Manitoba, Colúmbia Britânica e Toronto. Os contatos entre estes diferentes grupos se mantêm através de cartas, telefonemas, e-mail e/ou visitas. Essa característica é um exemplo da dialética que rege, numa escala global, o sistema ideológico ("todos somos menonitas") e a integração social interna da família, típica para as relações sociais pós-modernas dos menonitas. As integrações sistêmica e social se superpõem neste caso.

Uma análise das orientações religiosas dos 32 membros da geração filial mostra que é, predominantemente, a coerência religiosa que garante os fortes laços da família (ver figura 2). A religião torna-se, assim, o elemento essencial da integração sistêmica. A fé representa uma ideologia baseada numa linguagem simbólica comum e sustenta a ética dos menonitas. Assim, esta serve principalmente para a autolegitimação do grupo, conforme a teoria da estruturação. Como conseqüência da fé, o cristianismo menonita define a identidade social (Irmãos em Cristo), a fundamentação das práticas sociais do grupo (comunidade apostólica) e as intenções espirituais de cada um (salvação). Todavia, essa função fundamental é também raíz de vários cismas, como já foi o caso entre frisões e flamengos, e entre Irmãos Menonitas e Igreja Menonita. Recentemente este problema reapareceu quando a ação missionária dos menonitas obteve mais sucesso e criou grupos de menonitas brasileiros sem ascendência alemã. Os menonitas missionados buscam a sua identidade não nos moldes da cultura alemã menonita, mas sim, na universalidade do cristianismo anabatista. Essa situação acaba enfraquecendo gradativamente as forças de autosegregação nas comunidades menonita-alemãs. Hoje, os grupos que convivem em Curitiba, mantém - como menonitas - uma dupla estrutura parcialmente conflituosa entre a vertente alemã e a brasileira, não no sentido teológico, mas sim, no sentido das práticas cotidianas. Esta situação parece semelhante ao conflito entre as primeiras comunidades judia-cristãs e heleno-cristãs, mencionados nos Atos (Cap. 15, 6-27) e na Epístula aos Gálatos do Apóstolo Paulo (Cap. 2). Identidade étnica e universalismo político aparecem como os dois pólos dessa relação. 
FIGURA 2 - ÁRVORE GENEALÓGICA DE FAMÍLIA MENONITA COM INDICAÇÃO DE RELIGIÃO DE SEUS MEMBROS

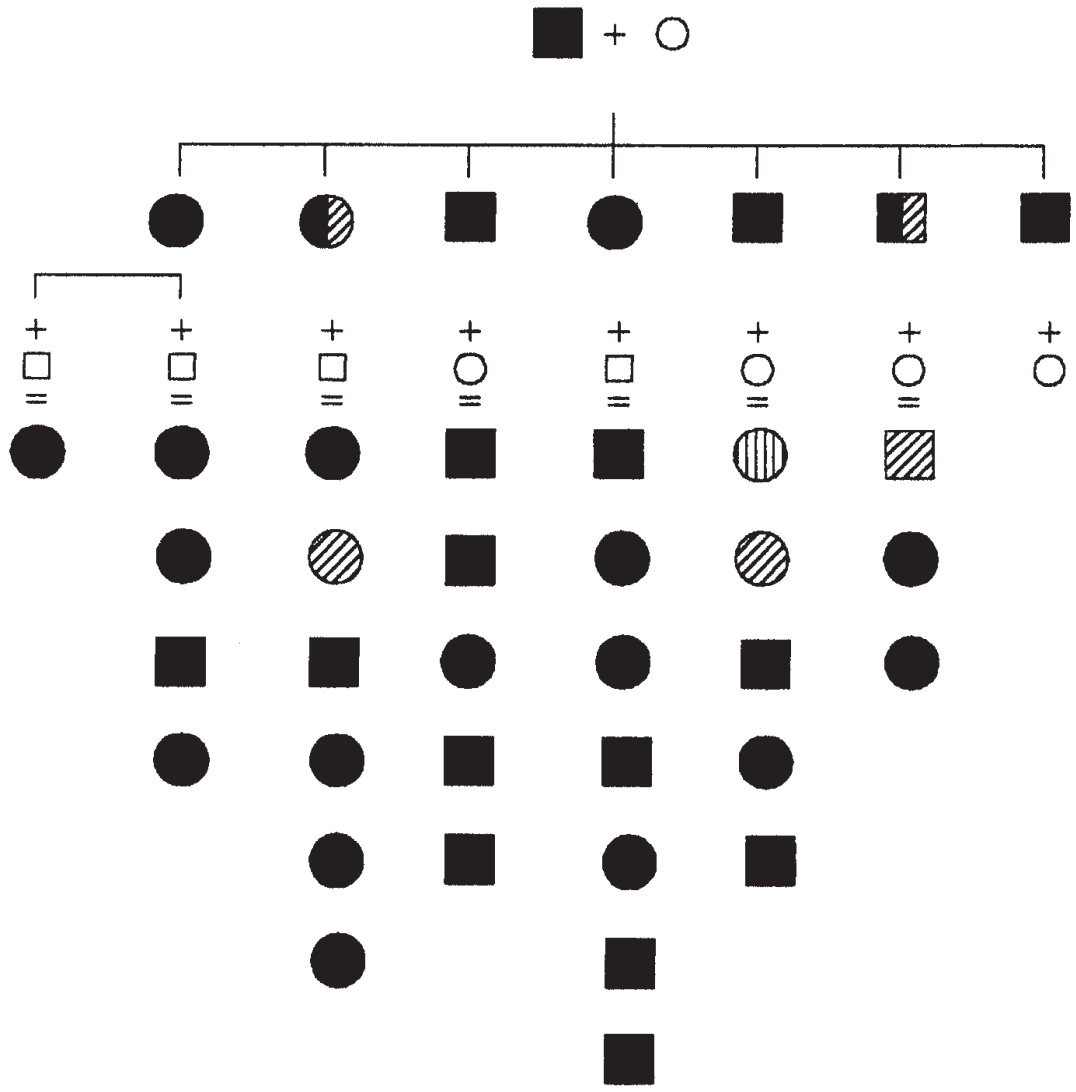

LEGENDA:

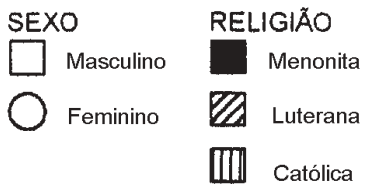

Na família pesquisada, as práticas sociais menonitas não puderam ser mantidas nos casos em que os migrantes não conseguiram montar um grupo de tamanho suficiente para exercê-las. Neste caso, eles procuravam comumente a integração com luteranos de descendência alemã, cujas semelhanças teológicas (principalmente na 
sua vertente pietista) facilitavam uma assimilação entre as duas denominações. Tanto na União Soviética quanto no Brasil, foram entidades protestantes que ajudaram ativamente os menonitas nas suas situações difíceis. A semelhança entre os sistemas ideológicos explica a travessia, até a conversão, entre essas denominações. Este foi também o caso de David* e sua esposa Ingrid*, que saíram do Stoltzplateau nos anos 40 em direção ao interior paranaense (Castro e Ponta Grossa). Lá, eles não encontraram um grupo estabelecido de menonitas e, por isso, associaram-se aos luteranos. Com a vontade de permanecer no âmbito menonita, o casal mudou-se, em 1955, junto com as suas filhas Gertrud* e Isabel ${ }^{*}$, para o Xaxim, onde já existia uma comunidade grande de Irmãos Menonitas. Somente o irmão delas não acompanhou a família, permanecendo no Segundo Planalto paranaense. As ações socioreligiosas da família pesquisada, mostram como a coesão religiosa atua como um fator social importante na fronteira entre as integrações social e sistêmica dos menonitas.

A homogeneidade da integração social (família) como da integração religiosa (menonita) não aparece no âmbito lingüístico. Geralmente, os grupos mais tradicionais são trilíngües. O Plaudietsch, um dialeto alemão-holandês, é muito falado no âmbito restrito da família e entre amigos próximos, garantindo a manutenção da integração social interna. Visto de uma perspectiva da cultura de transposição do migrante, o uso do Hochdeutsch, do alemão oficial, significa uma certa inserção num âmbito cultural maior e integra os menonitas aos inúmeros grupos de imigrantes oriundos de várias regiões da Alemanha. Essa capacidade lingüística facilita ainda o acesso ao mercado de trabalho no Brasil e ao sistema educacional da Alemanha. Conseqüentemente, não são poucos os menonitas que trabalham em Curitiba junto a empresas alemãs ou à cooperação técnica da Alemanha.

A terceira língua dos menonitas brasileiros é o português. O papel de uma terceira língua para os menonitas passou por várias substituições durante este século (ver figura 3). O avô Aron* falava quatro línguas: 0 russo e o ucraniano, além do Plaudietsch e do alemão. David* substituiu o russo e o ucraniano pelo português. Na terceira geração o russo e o ucraniano foram esquecidos, reforçando-se o uso do português. Hoje, na quarta geração, enquanto o português é exercido num âmbito mais amplo, o alemão e Plaudietsch ficaram restritos aos espaços lingüísticos da família e da igreja. Reproduz-se, desta forma, dentro do campo lingüístico, um processo de transposição cultural, o qual mostra que os menonitas estão saindo gradativamente dos seus padrões culturais tradicionais. Este processo não se restringe ao Brasil, parece universal 
entre os menonitas, como mostram também os casos dos grupos menonitas do Canadá, do Paraguai e da Alemanha.

FIGURA 3 - ÁRVORE GENALÓGICA DE FAMÍLIA MENONITA COM INDICAÇÃO DOS IDIOMAS FALADOS POR SEUS MEMBROS

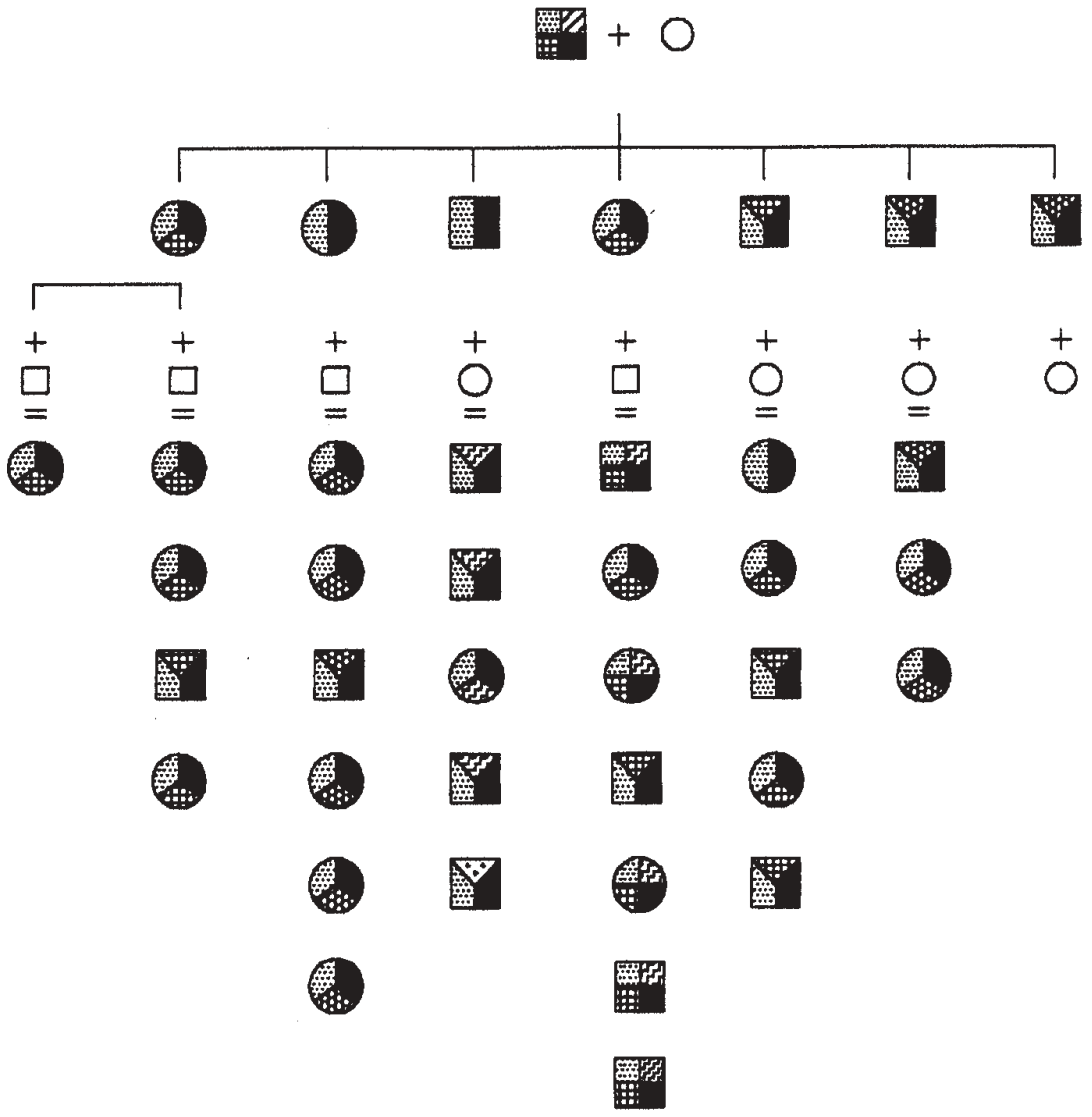

LEGENDA:

SEXO

$\square$ Masculino

Feminino
IDIOMA

Dialeto "Plattdeutsch" Ucraniano

Espanhol

Alemão Oficial

Português (Brasil)

Russo

Inglês 
Também a inserção econômica dos menonitas pode ser interpretada como elemento de uma cultura de transposição. A frustração do grupo menonita com a agricultura silvícola no Stoltzplateau levou vários de seus membros a saírem de lá diretamente para Curitiba ou, como no caso da família em análise, para o interior do Paraná. Nesses novos locais eles buscaram a vizinhança com grupos étnicos semelhantes (alemães e holandeses) e o reestabelecimento de uma agricultura parecida com as antigas experiências da Ucrânia e Rússia. A mudança da família de David*, nos anos 50, para Curitiba integrou-a ao contexto econômico menonita da produção leiteira e da "Cooperativa de Laticínios Curitiba Ltda". Gertrud* e Isabel*, filhas de pais "leiteiros", viveram uma mudança brusca de estilo de vida quando se casaram com dois professores menonitas. A mudança na vida particular destas aconteceu exatamente na época em que o processo de urbanização tomou força nos bairros do Xaxim e Boqueirão. Apesar do fato de ambos os professores atuarem no âmbito da educação menonita, eles participam, através do ensino em língua portuguesa, numa transformação decisiva da cultura menonita, abrindo novos espaços de transposição com a cultura brasileira. Até hoje, a educação representa um recurso altamente estimado entre os filhos das duas irmãs, principalmente por seu valor integrativo à sociedade brasileira e seu papel econômico.

A integração ao mercado capitalista urbano significou um grande desafio para o grupo menonita, fortemente irraigado a uma tradição rural. Observa-se, atualmente, uma individualização econômica entre os membros da família pesquisada, o que pode ser considerado resultado de um processo educacional moderno. Embora esta individualização coincida parcialmente com a ética da religião menonita, que se centra bastante na responsabilidade individual da fé (decisão individual para Cristo), a comunidade antigamente mantinha a sua coesão cultural e interação econômica solidária através do seu espírito comunal e de um sistema de cooperativismo. Na atualidade, estes elementos quase não existem mais entre os menonitas no meio urbano. Hoje, as inter-relações da família se reduzem quase exclusivamente no meio social e religioso. Raramente, o exercício das profissões é feito pelo conjunto da família, como era o caso da agricultura e da pecuária leiteira.

A comparação entre os grupos da família pesquisada indica que a urbanização encontra-se mais avançada entre os menonitas do Canadá e do Brasil (ver figura 4). Muitos dos menonitas da Alemanha apenas recentemente, quando chegaram da Rússia, deixaram o meio 
rural. Aqueles que permanecem na Rússia atuam ainda, até hoje, na agricultura. Observa-se também que outras famílias menonitas no Brasil, não pesquisadas neste estudo de caso, continuam no meio rural (como é o caso na Colônia Nova e em Witmarsum). Assim, o processo da transformação urbana induz uma mudança profunda no comportamento socioeconômico dos menonitas, tendo repercussões no âmbito religioso e até no familiar. Este conflito reproduz uma contradição da sociedade moderna em geral que existe entre o indivíduo e o grupo. Responder a este desafio da sociedade moderna será uma das grandes tarefas da cultura menonita no século XXI.

FIGURA 4 - ÁRVORE GENEALÓGICA DE FAMÍLIA MENONITA COM INDICAÇÃO DO TIPO DE OCUPAÇÃO DE SEUS MEMBROS

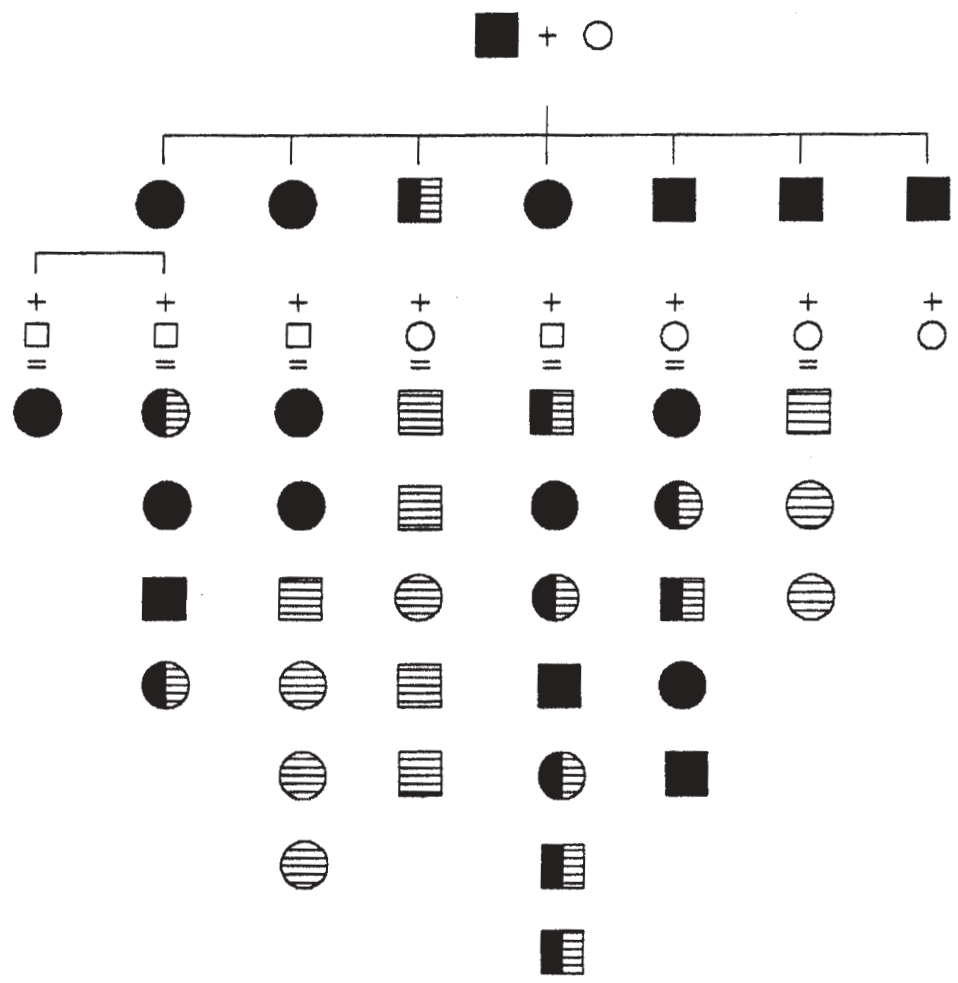

LEGENDA:

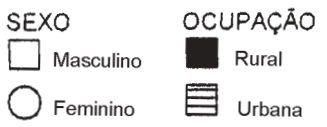




\section{CONSIDERAÇÕES FINAIS}

Este estudo interpreta a cultura menonita como uma cultura de transposição impregnada por experiências altamente diferenciadas no seu percurso histórico. Cada cultura de transposição vive cotidianamente a dialética entre integração social, baseada nas interações diretas das pessoas, e integração sistêmica, mantendo as estruturas sistêmicas necessárias para o grupo. Os menonitas não fogem à regra. Essa dialética só pode ser entendida quando analisada em contextos diferentes e como processo de permanente oscilação entre o social e o sistema.

No caso dos menonitas brasileiros, o conflito entre a cultura nacional - como sistêmica - e a cultura étnica - como social - surge em virtude das preocupações internas do grupo em preservar os seus recursos culturais, os quais se mostraram valiosos em toda a trajetória do grupo. Essa preocupação revela que, também no interior do grupo menonita, a dialética entre comportamento social e sistema religioso atua como fator diferenciador. As experiências menonitas, numa visão de fora, parecem poderem ser úteis para outros grupos de imigrantes enquanto referências e reflexões importantes sobre a problemática, sobretudo num ambiente multi-cultural como é o caso do Brasil.

Vale mencionar, neste contexto, que a história menonita casualmente reproduz conflitos que já eram conhecidos desde a época bíblica e descritos nitidamente no livro sagrado dos Cristãos. Desta forma, a discussão da temática pode abrir um espaço comunicativo para todas as denominações de uma sociedade cristã como a brasileira. Os conflitos dos judeus com os seus povos vizinhos no Canaã, discutidos amplamente nos livros históricos do Velho Testamento (Josué, Samuel, Reis, Crônicas, etc.) como igualmente a disputa entre os grupos judeucristãos e heleno-cristãos dos Atos e das Epístolas do Apóstolo Paulo trazem conotações que, até hoje, podem ser interpretadas através do conflito entre integração social e sistêmica. Entender essas relações é, assim, não apenas importante para os menonitas e teólogos, mas também, para qualquer outro grupo de imigrantes, que viva nas fronteiras sociais entre as culturas nacional e forasteira. 


\section{REFERÊNCIAS}

ANDREAZZA, M. L. O paraíso das delícias. Um estudo da imigracão ucraniana. Curitiba: Aos Quatro Ventos, 1999.

CANADIAN MENNONITE ENCYCLOPEDIA ONLINE. Disponível em: $<$ www.hms.ca/encyclopedia/contents>

CLOKE, P.; PHILO, C.; SADLER, D. Approaching Human Geography. An introduction to contemporary theoretical debates. London: Paul Chapman, 1991.

GERLACH, H. Bildband zur Geschichte der Mennoniten. UelzenOldenstadt: Preuschoff, 1980.

GIDDENS, A. A constituição da sociedade. São Paulo: Martins Fontes, 1989.

GOULART, M. C. R. K.; FRAGA, N. C. Vale dos índios, Vale dos imigrantes. Blumenau: Cultura em Movimento, 2000.

HABERMAS, J. Theorie des kommunikativen Handelns. 2. Band: Zur Kritik der funktionalistischen Vernunft. Frankfurt/M.: Suhrkamp, 1981.

HORBATIUK, P. Imigração ucraniana no Paraná. Porto União: Uniporto, 1989.

KLASSEN, P. P. Die russlanddeutschen Mennoniten in Brasilien. Band 1: Rio Alto Krauel und Stoltzplateau in Santa Catarina. BolandenWeiherhof: Mennonitischer Geschichtsverein, 1995.

KLASSEN, P. P. Die russlanddeutschen Mennoniten in Brasilien. Band 2: Siedlungen, Gruppen und Gemeinden in der Zerstreuung. BolandenWeiherhof: Mennonitischer Geschichtsverein, 1998.

KNISS, F. Rethinking boundaries: agenda for the social study of anabaptists. Newsletter of the Anabaptist Sociology and Anthropology Association, v. 4, n. 3, p. 2-6, 1999.

KOKUSKA, P. M. Nos rastros dos imigrantes poloneses. Curitiba: Arins, 2000. 
MARTINEZ, J. F. História e teologia da Reforma Anabatista. Um desafio atual. Campinas: Ed. Cristã Unida, 1997.

MARTINS, W. Um Brasil diferente: ensaio sobre fenômenos de aculturação no Paraná. 2. ed. São Paulo: Queirós, 1989.

MELLO NETO, C. O anarquismo experimental de Giovanni Rossi (de Poggio al Maré à Colônia Cecília). 2. ed. Ponta Grossa: Editora UEPG, 1998.

MERTENS, G. Geschichte der Mennonitensiedlung "Colônia Nova". In: PAULS JÚNIOR, P. P. (Org.). Mennoniten in Brasilien. Gedenkschrift zum 50 Jahr-Jubilaeum ihrer Einwanderung 1930-1980. Witmarsum: Festkomitee für die Jubiläumsfeier, [19-]. p. 137-189.

OBERACKER, K. H. Die Deutschen in Brasilien. In: FRÖSCHLE, H. (Org.). Die Deutschen in Lateinamerika. Schicksal und Leistung. Tübingen, Basel: Horst Erdmann, 1979. p. 169-300.

PAULS JÚNIOR, P. P. (Org.). Mennoniten in Brasilien. Gedenkschrift zum 50 Jahr-Jubilaeum ihrer Einwanderung 1930-1980. Witmarsum: Festkomitee für die Jubiläumsfeier, 1980a.

PAULS JÚNIOR, P. P. Urwaldpioniere. Persoenliche Erlebnisse Mennonitischer Siedler aus den ersten Jahren am Krauel und vom Stoltzplateau, S.C. Curitiba: Festkomitee für die Jubiläumsfeier, 1980b.

PENNER, H. Weltweite Bruderschaft. Ein mennonitisches Geschichtsbuch. Karlsruhe: Schneider, 1955.

SAHR, W.-D. Em meio aos mundos um mundo no meio: vivência e significado da migração nas sociedades caribenhas. MERTINS, G.; SKOCZEK, M. (Orgs.). Migraciones de la población latinoamericana y sus efectos socioeconómicos. Warszawa: Universytet Warszawski, 1998. p. 213-231.

SCHUETZ, A.; LUCKMANN, T. Strukturen der Lebenswelt. Frankfurt/ M.: Suhrkamp, 1979.

URRY, J. Of borders and boundaries: reflections on Mennonite unity and separation in the modern world. Mennonite Quarterly Review, July 1999. Disponível em: <www.goshen.edu/mqr/pastissues/july99urry.html> 
WACHOWICZ, R. O camponês polonês no Brasil. Curitiba: Fundação Cultural de Curitiba, 1981.

WAIBEL, L. Die europäische Kolonisation Südbrasiliens. Bonn: [s. n.], 1955. (=Colloquium Geographicum, 4).

WALDENFELS, B. Topographie des Fremden. Frankfurt/M.: Suhrkamp, 1997.

WERLEN, B. Sozialgeographie alltaeglicher Regionalisierungen. Band 2: Globalisierung, Region und Regionalisierung. Stuttgart: Franz Steiner, 1997.

WERLEN, B. Sozialgeographie. Bern: Haupt, 2000.

WISOTZKI, E. Die Überlebensstrategien der russlanddeutschen Mennoniten. Bonn, 1992. Tese (Doutorado) - Friedrich-WilhelmsUniversitaet. 